\title{
First Reported Death of a Postpartum Woman Due to Coronavirus Disease 2019 in Nepal: A Lesson Learnt Shrestha AP, ${ }^{1}$ Bhushal N, ${ }^{2}$ Shrestha $A,{ }^{3}$ Tamrakar $D,{ }^{3}$ Adhikari $P,{ }^{4}$ Shrestha $P,{ }^{4}$ Shrestha $A,{ }^{4}$ Karmacharya B, ${ }^{4}$ Basnet $S,{ }^{1}$ Tamrakar SR, ${ }^{5}$ Shrestha $\mathrm{R}^{1}{ }^{1}$ Shrestha $\mathrm{R}^{6,7}$
}

${ }^{1}$ Department of General Practice and Emergency Medicine

${ }^{2}$ Department of Microbiology,

${ }^{3}$ Department of Community Medicine,

${ }^{4}$ Department of Public Health and Community Program,

${ }^{5}$ Department of Obstetrics and Gynecology,

${ }^{6}$ Department of Pharmacology,

${ }^{7}$ Pharmacovigilance Unit/Research and Development Division,

Dhulikhel Hospital Kathmandu University Hospital,

Kathmandu University School of Medical Sciences,

Dhulikhel, Kavre, Nepal.

\section{Corresponding Author}

Anmol Purna Shrestha

Department of General Practice and Emergency Medicine

Dhulikhel Hospital Kathmandu University Hospital, Kathmandu University School of Medical Sciences, Dhulikhel, Kavre, Nepal.

E-mail: shresthanmol@kusms.edu.np

\section{Citation}

Shrestha AP, Bhushal N, Shrestha A, Tamrakar D, Adhikari $P$, Shrestha P, et al. First Reported Death of a Postpartum Woman Due to Coronavirus Disease 2019 in Nepal: A Lesson Learnt. Kathmandu Univ Med J. 2020;COVID-19 Special Issue 70(2):117-9.

\begin{abstract}
The first case of coronavirus disease 2019 was reported on December 31, 2019 in Wuhan, China where the average case fatality rate was $6.1 \pm 2.9 \%$. There are 453 deaths as of September 24, 2020 in Nepal. We report the first death of a 29-years-old postpartum woman due to COVID-19 in Nepal who was referred from a rural health center to Dhulikhel Hospital. On arrival, she was taken to the acute respiratory zone of the emergency department to provide immediate lifesaving procedures. Despite the repeated resuscitative measures, return of spontaneous circulation could not be achieved. The real time polymerase chain reaction test was positive. Our case report highlights the importance of early clinical suspicion, importance of "safety first" in healthcare settings, and the chain of management in such patients. We consider the fact that a postpartum woman registered as the first case of COVID-19 related death in Nepal to be an area of further study.
\end{abstract}

\section{KEY WORDS}

Coronavirus, Emergency department, Personal protective equipment, Postpartum death, Real time polymerase chain reaction, Resuscitation 


\section{INTRODUCTION}

Coronavirus disease 2019 (COVID-19) caused by SARS-COV2 was first reported as a case of pneumonia of unknown etiology on December 31, 2019 in Wuhan, China. ${ }^{1}$ Globally, there are 7,448,386 active cases, 982,742 deaths and $23,708,636$ recovered cases as of September 24, 2020. ${ }^{2}$ Nepal had its first imported case of COVID-19 on January 25, 2020. ${ }^{3}$ There are 18437 active cases, 453 deaths and 50411 recovered cases as of September 24, 2020. ${ }^{4}$ Proper case detection, segregation and management along with the appropriate safety measures by the health care provider in the Emergency Department (ED) is very critical to clinical management in COVID-19 situation. We discuss the first reported death on May 14, 2020 due to COVID-19 in a postpartum woman in this case report with minimal exposure of the health care providers at ED. , $^{5}$

\section{CASE REPORT}

A twenty-nine-year-old female from Bahrabise Municipality, Sindhupalchowk was referred from Bahrabise Primary Health Care Center (PHCC) on May 14, 2020. The medical record from the PHCC revealed that she had difficulty in breathing, multiple bouts of cough with blood streaked sputum and intermittent fever from two days prior to presentation. After initiation of supportive treatment, she was referred to Dhulikhel Hospital for further management with a differential diagnosis of pulmonary embolism and planned for real time quantitative polymerase chain reaction test (RT-qPCR) for SARS-COV 2. The further history revealed that she had delivered a preterm child nine days prior to presentation at Tribhuvan University Teaching Hospital, Maharajgunj, Kathmandu.

Dhulikhel Hospital started its preparedness for the outbreak and surge of potential CVOID-19 patients by adding different triage areas, and a separate acute respiratory infection (ARI) zone in the ED to avoid cross contamination. On arrival at the triage area of Dhulikhel Hospital, she was evaluated by on-duty triage nurse and on-duty consultant from the Emergency Department at the triage area. Due to absence of clear epidemiological criteria to suspect COVID-19 at that phase of outbreak in Nepal and the critical state of patient (gasping on arrival), she was immediately taken to ARI zone of the ED to provide immediate lifesaving procedures, where aerosol generating procedures like cardiopulmonary resuscitation and intubation are performed with utmost precautions. Unfortunately, the patient was declared dead despite adequate resuscitative measures. Chest X-ray showed extensive air space opacification with air bronchogram predominantly at bilateral middle and lower zone suggestive of consolidation; ill-defined air space at bilateral lung parenchyma likely to be Acute respiratory distress syndrome (ARDS) with mild cardiomegaly (fig. 1). As per clinical history and X-ray finding, the immediate cause of death was bilateral pneumonia with acute pulmonary edema and antecedent cause is consistent with COVID-19.

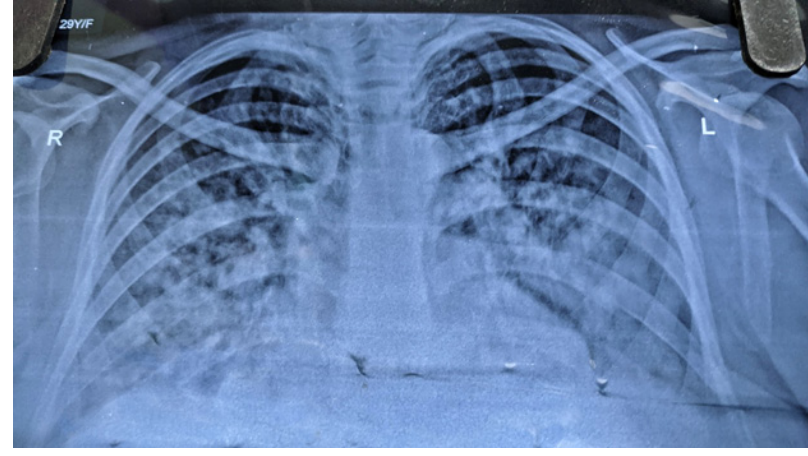

Figure 1. Chest X-ray of the patient showing extensive air space opacification with air bronchogram predominantly at bilateral middle and lower zone suggestive of consolidation; ill-defined air space at bilateral lung parenchyma.

The patient's clinical presentation and radiological features were both suggestive of COVID-19. The patient's swab was collected from the nasopharyngeal area and tracheal secretion and sent for RT-qPCR test. The RT-qPCR test of patient's swab for COVID-19 was reported positive. After appropriate disinfection of the deceased body, it was transferred to the mortuary of the Department of Forensic Medicine following recommended guidelines provided by the Government of Nepal. ${ }^{7}$ With the guidance from the Department of Forensic Medicine, the body of the deceased patient was double packed in a dead body management bag.

All staff involved in patient management had followed safety measures with appropriately donned personal protective equipment (PPE). They were quarantined as per risk assessment and tested negative for COVID-19 later on.

\section{DISCUSSION}

Our case report highlights the importance of early clinical suspicion, importance of "safety first" in healthcare settings, and the chain of management required for management of a critically ill COVID-19 patient in a healthcare facility. The timely case segregation by the triaging system in the hospital led to proper management of the patient in the dedicated ARI Zone in the hospital. This resulted in minimal exposure of the health care providers involved in patient care avoiding the cross contamination to other staff and patients in the department and beyond in the hospital premises. This fact has also been highlighted by WHO as it stated the importance of the eight pillars of COVID-19 preparedness and response planning. ${ }^{8}$ A postpartum woman being registered as the first case of COVID-19 related death in Nepal is also an area of exploration in itself.

Women are less likely to have severe disease or die due to COVID-19 as compared to men. Moreover, there is a $60 \%$ lesser chance of intensive care requirement in the women of reproductive age as compared to men matched for age. ${ }^{9}$ However, cardiovascular, respiratory or coagulation related physiological changes increase the risk of COVID-19 related morbidity and thus are more likely to need intensive care. ${ }^{10,11}$ 
The presence of comorbidities in pregnancy may increase the likelihood of development of serious complications. ${ }^{12}$ Hence, obstetrics and maternal-fetal medicine practice have recently undergone overwhelming changes to adapt to the pandemic which is reflected by constantly updated national and international guidelines. ${ }^{13-15}$

The average case fatality rate of COVID-19 in China was $6.1 \pm 2.9 \%{ }^{16}$ There are a few preliminary studies done in the developed countries regarding the effect of COVID-19 on pregnancy, delivery, and postpartum period. We have very scarce literature regarding maternal mortality due to COVID-19 for developing countries like Nepal. Preliminary reports from the World Health Organization have shown that approximately $8 \%$ of pregnant or postpartum women with COVID-19 have severe disease and approximately $1 \%$ are critically ill. ${ }^{5}$ Study done at New York hospitals showed that COVID-19 disease severity in pregnant women $86 \%$ mild, $9.3 \%$ severe, and $4.7 \%$ critical which was similar to that in nonpregnant adults. ${ }^{17}$ As per Centers for Disease Control and Prevention (CDC), there have been 20798 COVID-19

\section{REFERENCES}

1. Novel Coronavirus (2019-nCoV), Situation report - 1, 21 January, 2020 World Health Organization. Available from: https://www.who. int/docs/default-source/coronaviruse/situation-reports/20200121sitrep-1-2019-ncov.pdf?sfvrsn=20a99c10_4 (accessed 24 September 2020).

2. Coronavirus Update (Live): $32,139,949$ Cases and 982,742 Deaths from COVID-19 Virus Pandemic - Worldometer. Available from: https://www.worldometers.info/coronavirus/ (accessed 24 September 2020).

3. Health Sector Response to Novel Coronavirus (2019-nCoV), Ministry of Health and Population, Government of Nepal. Available from: https://www.mohp.gov.np/attachments/article/543/Health\%20 Sector\%20Response\%20to\%20Novel\%20Coronavirus\%20(2019nCoV)\%20English.pdf (accessed 24 September 2020).

4. Nepal COVID-19 Statistics. Available from: https://portal.edcd.gov. $\mathrm{np} /$ covid19/index.html (accessed 24 September 2020).

5. COVID-19, Situation report-118, World Health Organization. Available from: https://www.who.int/docs/default-source/ coronaviruse/situation-reports/20200517-covid-19-sitrep-118. pdf?sfvrsn=21c0dafe_10 (accessed 9 June 2020).

6. Basnet L. The story of Nepal's first COVID-19 fatality. Available from: https://www.nepalitimes.com/latest/the-story-of-nepals-first-covid19-fatality/ (accessed 8 June 2020)

7. Dead Body Management Protocol, V3_15-06-2020, Ministry of Health and Population, Government of Nepal. Available from: https:// drive.google.com/file/d/1dbTpfm5aysdY9utUcOXLEbuZ-VUxQ5y5/ view?usp=embed_facebook (accessed 24 September 2020).

8. COVID-19 Strategic Preparedness and Response Plan, Operational planning guidelines to support country preparedness and response. Available from: https://www.who.int/docs/default-source/ coronaviruse/covid-19-sprp-unct-guidelines.pdf (accessed 24 September 2020).

9. López M, Gonce A, Meler E, et al. Coronavirus Disease 2019 in Pregnancy: A Clinical Management Protocol and Considerations for Practice. Fetal Diagn Ther. 2020;47:519-28.

10. Di Mascio D, Khalil A, Saccone G, et al. Outcome of coronavirus spectrum infections (SARS, MERS, COVID-19) during pregnancy: a systematic review and meta-analysis. Am J Obstet Gynecol MFM. 2020;2:100107. cases, 205 admitted to ICU, 77 requiring ventilation and 44 deaths among pregnant women in the United States between January 22 September 08, 2020. ${ }^{18}$

Reports on MMR estimates by the Maternal Mortality Estimation Inter-Agency Group (MMEIG) show that there has been a decline in maternal mortality in Nepal between 2000-2017. ${ }^{19}$ The demographic survey in Nepal reported the maternal mortality ratio in 2016 to be 239 deaths per 100,000 live births for seven years constantly before the survey. ${ }^{20}$ However, the impact of COVID-19 on maternal health requires further research. ${ }^{21}$

\section{CONCLUSION}

Early clinical suspicion, early refferal and appropriate timely management are required for management of a critically ill COVID-19 patient in pregnancy and postpartum. We therefore recommend further research to understand the effect of COVID-19 on maternal health leading to maternal morbidity and mortality.

11. Mahase E. COVID-19: Pregnant women with virus are more likely to need intensive care, study finds. BMJ; 370. Epub ahead of print 2 September 2020. DOI: 10.1136/bmj.m3391.

12. SARS-CoV-2 Infection and COVID-19 During Pregnancy: A Multidisciplinary Review. Elsevier Enhanced Reader. DOI: 10.1016/j. mayocp.2020.05.011.

13. Novel Coronavirus 2019 (COVID-19). Available from: https:// www.acog.org/en/Clinical/Clinical Guidance/Practice Advisory/ Articles/2020/03/Novel Coronavirus 2019 (accessed 22 September 2020).

14. Coronavirus (COVID-19) infection and pregnancy. Royal College of Obstetricians \& Gynaecologists. Available from: https://www.rcog. org.uk/en/guidelines-research-services/guidelines/coronaviruspregnancy/ (accessed 24 September 2020).

15. Nepal Society of Obstetricians and Gynecologists. NESOG Clinical Practice Guidance for Management of Reproductive Health during COVID-19 Pandemic. Kathmandu: NESOG; 2020. Available from: http://www.nesog.org.np/images/resources/nesog_guideline.pdf (accessed 24 September 2020).

16. Mi Y, Huang $T$, Zhang J, et al. Estimating the instant case fatality rate of COVID-19 in China. Int J Infect Dis. 2020; 97: 1-6.

17. Breslin N, Baptiste C, Gyamfi-Bannerman C, et al. Coronavirus disease 2019 infection among asymptomatic and symptomatic pregnant women: two weeks of confirmed presentations to an affiliated pair of New York City hospitals. Am J Obstet Gynecol MFM. 2020; 2: 100118.

18. Coronavirus Disease 2019 (COVID-19). Centers for Disease Control and Prevention. Available from: https://www.cdc.gov/coronavirus/2019ncov/cases-updates/special-populations/pregnancy-data-oncovid-19.html (2020, accessed 17 September 2020).

19. Maternal mortality in 2000-2017, Internationally comparable MMR estimates by the Maternal Mortality Estimation Inter-Agency Group (MMEIG); WHO, UNICEF, UNFPA, World Bank Group and the United Nations Population Division. Available from: https://www.who. int/gho/maternal_health/countries/npl.pdf?ua=1 (accessed 24 September 2020).

20. Demographic and Health Survey Key Findings, Nepal. Available from: https://dhsprogram.com/pubs/pdf/SR243/SR243.pdf (2017, accessed 17 September 2020).

21. Hantoushzadeh S, Shamshirsaz AA, Aleyasin A, et al. Maternal death due to COVID-19. Am J Obstet Gynecol. 2020;223:109.e1-109.e16. 